\title{
Building Information Modeling-A Quick Overview
}

\author{
Panjehpour* \\ Department of Civil Engineering, INTI International University, Malaysia
}

*Corresponding author: Panjehpour, Associate Professor, Department of Civil Engineering, Faculty of Engineering and Quantity Surveying, INTI International University, Malaysia.
Received Date: April 01, 2019

Published Date: April 15, 2019

\begin{abstract}
According to the US national building information model standard project committee, "Building Information Modeling (BIM) is a digital representation of physical and functional characteristics of a facility." The American institute of architects has defined BIM as "a model-based technology linked with a database of project information". As BIM method is still evolving, there is not yet a unique single standard for it. The UK has introduced some guidelines for BIM implementation as opposed to the US, which left it to the users in a competitive way in order to enhance and advance BIM based on the construction demand.
\end{abstract}

Keywords: BIM; Digital; Building

\section{Introduction}

According to the US national building information model standard project committee, "Building Information Modeling (BIM) is a digital representation of physical and functional characteristics of a facility." The American institute of architects has defined BIM as "a model-based technology linked with a database of project information" [1]. As BIM method is still evolving, there is not yet a unique single standard for it. The UK has introduced some guidelines for BIM implementation as opposed to the US, which left it to the users in a competitive way in order to enhance and advance BIM based on the construction demand. Beyond three-dimensional design of structures, BIM has progressed by proposing its 4 th to 7 th dimensions as time, cost, sustainability and life cycle respectively, though these classifications have not been globally approved [1]. The objective of this review is to shed some light on the process and purposes of BIM in order to shape our thinking over the BIM. The current users of BIM lay emphasis on the importance of a clear understanding of BIM before its implementation [2,3]. Looking from another view, the construction building is simulated using BIM by providing electronic documents including overall layout, schedule, process and materials which play a significant role in the purchase of residential unit before physical completion of building [4]. When customers observe the 3D animation of building and virtually walk through their future construction unit, by going through all details of material, even the contact of material supplier, they feel secure regarding their purchase. BIM reveals the potential risks during physical construction and enables the users to improve the relative potential risk, through the feedbacks in simulation process, which significantly affects the quality of construction implementation [4]. BIM has been introduced as a catalyst for innovation and productivity in construction industry which may contribute to eradicating poverty in developing countries [5]. Prefabrication construction products are practical instances of BIM as the designer can examine whether the product is fitted properly the virtual 3D building. This increases confidence of the designer when innovating a product as unfitting has been an issue for prefabricated building elements. BIM could enhance the construction economy in a longterm in developing countries, as it first requires fundamental tools and knowledge.

BIM is discussed as three main dimensions in the construction projects: a product to describe a building, a process of gathering information and a system to increase the quality of the building. It facilitates the way towards sustainable building throughout the construction life cycle [6]. In fact, the aforementioned dimensions have considerable overlap as the electronic documentations of building represent three of these dimensions. The construction sustainability falls under the concept of green BIM. In brief, life cycle design, cost-saving and building safety are good indicators of environmental, economic and social aspects of green BIM respectively. BIM integrates constructional elements in form of 2D and 3D intelligent objects linked to informative database such as 
geographical location, material supplier contact, contractor contacts and even the date when a decision was made for a particular issue on an element together with information on those involved in the decision-making [7]. This aspect of BIM is called BIM objects, which plays a significant role in architectural design of buildings. The phrase "intelligence" attributes to objects, includes parametricallydefined graphical and non-graphical information, provided by the main BIM collaborators such as architectural, structural and MEP designers, as functional relationship among building elements. When revision is made on one element, the other elements will be automatically revised according to the functional link among them [7]. This aspect of BIM is called parametric design and BIM automation [8]. The still-evolving BIM method is undergoing some advances and new proposals. As an instance, a BIM-based virtual environment supported by virtual reality has been introduced. The aim of this proposal is to utilise BIM and virtual real technology seamlessly to provide fire evacuation guidance considering robustness for effective fire emergency management $[9,10]$. A BIM-based electronic procurement prototype, translating building information modeling to building energy modeling and developing mobile BIM barcode-based automated facility management system are some recent advanced proposal regarding BIM [11-13]. The analysis indicates that information system (IS) somewhat serves as a reference discipline and the theories used in IS research are also informing contemporary BIM research [14].

BIM is applied to three main construction project phases, which are pre-construction, construction and post-construction [15]. In other words, BIM process provides all required documentations before physical building construction. During the construction, all collaborative teams are integrated in a platform and see the progress of building as well as sudden or urgent changes in the design of building. After the completion of construction project, the documents and sources, which have already integrated into a single platform can be utilised for building maintenance. These are the beauty of BIM method, which makes it comprehensive and applicable to all phases of building. BIM is a set of digital tools for managing construction projects [15]. In fact, BIM is more than a set of tools. It integrates many digital tools for its objectives. According to the current practice of BIM by Autodesk Company, one of the core objectives of BIM implementation is clash detections before physical implementation of building as shown in Figure 1.

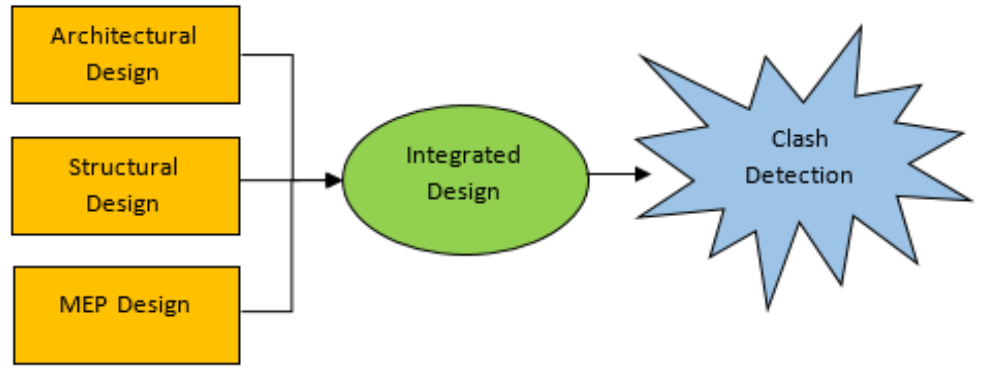

Figure 1: Clash detection using BIM method.

It is attained by a cloud-based platform, which integrates the architectural, structural, and MEP design into a single file by using a common format. The cloud-based platform enables the users to detect the clashes while integrating the design models and revise the models through the platform. All the modifications with the date, time and contact of collaborators who made the decision are digitally recorded. Therefore, the digital tools and software are becoming available for the users and perfect implementation of BIM is within the reach.

\section{Acknowledgement}

The author appreciates the scientific supports from the centre for advanced concrete technology (CACT).

\section{Conflict of interest}

No conflict of interest.

\section{References}

1. Wikipedia (2019) Building information modeling, The Free Encyclopedia.

2. Btoush M, AT Haron (2017) Understanding BIM Adoption in the AEC Industry: The Case of Jordan. IOP Conference Series: Materials Science and Engineering 271: 012044.
3. Mohd Ahnuar E (2019) What is BIM? A Need for A Unique BIM Definition. MATEC Web of Conferences. 266(05005): 6.

4. Dong RR (2017) The Application of BIM Technology in Building Construction Quality Management and Talent Training. EURASIA J Math Sci Tech 13(7):4311-4317

5. Bui NC, Merschbrock, BE munkvold (2016) A review of building information modeling for construction in developing countries. in Creative construction conference 2016. Norway pp.487-494.

6. Soltani S (2016) The Contributions of Building Information Modelling to Sustainable Construction. World Journal of Engineering and Technology 04(02): 193-199.

7. Boukaraa A, Naamaneb A (2015) A Brief Introduction to Building Information Modeling (BIM) and its interoperability with TRNSYS. Journal of Renewable Energy and Sustainable Development 1(1): 4.

8. Bhuskade S (2015) Building Information Modeling (BIM). International Research Journal of Engineering and Technology 2(2): 7.

9. BinWang HL, Yacine Rezgui, Alex Bradley, Hoang N Ong (2014) BIM Based Virtual Environment for Fire Emergency Evacuation. The Scientific World Journal, 2014: 22 pages.

10. Yu-Shen Liu, Heng Li, Haijiang Li, Pieter Pauwels, Jakob Beetz (2015) Recent Advances on Building Information Modeling. The Scientific World Journal, 2015: 2 pages.

11. António Aguiar Costa, António Grilo (2015) BIM-Based E-Procurement: An Innovative Approach to Construction E-Procurement. The Scientific World Journal, 2015: 15 pages. 
12. WoonSeong Jeong JB, Mark J Clayton, Jeff S Haberl, Wei Yan (2014) Translating Building Information Modeling to Building Energy Modeling Using Model View Definition. The Scientific World Journal, 2014: 21 pages.

13. Yu-Cheng Lin, Y Chih S, Yen-Pei Chen (2014) Developing Mobile BIM/2D Barcode-Based Automated Facility Management System. The Scientific World Journal, 2014: 16 pages.
14. Merschbrock C, BE Munkvold (2012) A Research Review on Building Information Modeling in Construction-An Area Ripe for IS Research. Communications of the Association for Information Systems 31.

15. Aryani Ahmad Latiffi, Suzila Mohd, Narimah Kasim, Mohamad Syazli Fathi (2013) Building Information Modeling (BIM) Application in Malaysian Construction Industry. International Journal of Construction Engineering and Management 2(4A): 1-6. 